\title{
Electrochemical Synthesis of $\mathrm{CeB}_{6}$ Nanotubes
}

\author{
H. B. Kushkhov, M. K. Vindizheva, R. A. Mukozheva, A. H. Abazova, M. R. Tlenkopachev \\ Kabardino-Balkar State University, Nalchik, Russia \\ Email: karashaeva@mail.ru, karashaeva@yahoo.com
}

Received November 2013

\begin{abstract}
This work presents the results of joint electroreduction of tetrafluorborate and cerium-ions, and determines the conditions of electrochemical synthesis of cerium borides in $\mathrm{KCl}-\mathrm{NaCl}$ melts at the $973 \mathrm{~K}$ on tungsten electrode by the linear and cyclic voltammetry. Based on the current-voltage studies the optimal modes of cerium boride electrodeposition were found.
\end{abstract}

\section{KEYWORDS}

\section{Molten Chloride; Linear and Cyclic Voltammetry; Cerium Borides; High Temperature Electrosynthesis; Nanotubes}

\section{Introduction}

Borides of rare earth metals (REM) are widely used in various fields of modern technology. The electrochemical synthesis of rare-earth borides at moderate temperatures $(973-1023 \mathrm{~K})$ is a cost-effective alternative to the direct solution-phase synthesis. The increased interest in the development of new efficient methods of producing rare earth borides are due to remarkable properties of these materials, such as chemical inertness, heat resistance, a wide range of electrochemical and magnetic properties, etc. There is an indication of the using possibility cerium hexaboride for refractory production for use in neutral or reducing atmosphere and in vacuum at temperatures of $2000^{\circ} \mathrm{C}$ or higher [1].

Electroreduction from the molten salts is a specific method for the preparation of compounds of elements such as refractory metals, actinides and rare earth metals [2]. Manifold variations of electrolytic production of metals and compounds based on them-this is a great selection of solvent, a variety of chemical and electrochemical characteristics of process and a temperature range, which is suitable for the process.

Of the various methods for the synthesis of cerium borides is the closest way to get them through the electrolysis of molten media [3]. Electrolysis was carried out in graphite crucibles, serving both the anode and a cathode made of graphite or molybdenum. The composition of the bath electrolysis includes oxides of rare earth metals and boric anhydride with additives of fluorides of alkali and alkaline earth metals to reduce the temperature and viscosity of the bath. Temperature electrolysis mixture was $1223 \mathrm{~K}-1273 \mathrm{~K}$, the voltage on the bath was $3.0-15.0 \mathrm{~V}$, current density was $0.3-3.0 \mathrm{~A} / \mathrm{cm}^{2}$. The composition of the bath for cerium hexaboride obtaining was: $\mathrm{CeO}_{2}+2 \mathrm{~B}_{2} \mathrm{O}_{3}+\mathrm{CeF}_{3}$.

As noted in work [3], the obtaining of the individual boride phase is practically impossible or very difficult. The disadvantages are also high temperature of synthesis and complexity of the product separation from the molten electrolyte due to the low solubility of borates and fluoride, contamination by-products, such as borates.

Thus, in view of the increasing use of rare earth metals and various materials on their basis and with the addition of rare earth metals in the various fields of science and technology, it is becoming an urgent task of obtaining these materials. A promising way to obtain rare earth, their alloys with other metals is the electrolysis of molten salts REM, as well as mixtures thereof.

For effective use of the electrolytic method of producing of metallic cerium and their alloys and compounds are necessary to have reliable information about electrochemical behavior of complexes formed by cerium ions in molten salts, and joint electroreduction with components connections.

Products quality of rare earth borides is determined by the purity and dispersion, namely original powder grain size, from which it is made. The product quality is higher when the grain size of compounds powder is smaller.

Previously, we have investigated the processes of joint electroreduction of rare-earth metals with boron ions in $\mathrm{KCl}-\mathrm{NaCl}$ and $\mathrm{KCl}-\mathrm{NaCl}-\mathrm{CsCl}$ melts at different elec- 
trodes. It is shown that the electroreduction of fluoroborate ion occurs at more positive potentials than deposition potential of metallic cerium [4-6].

In the works [7-10] the electrochemical behavior of boron, the laws of electrode processes at its refining, the solubility of boron compounds in molten alkali metal chlorides are studied. In literature the processes of joint electroreduction cerium and boron ions in halide melts on a tungsten electrode are poorly understood.

The aim of this work is to study the process of joint electroreduction of cerium ions with fluoroborate ions in molten equimolar $\mathrm{KCl}-\mathrm{NaCl}$ on the tungsten electrode and the electrochemical synthesis of cerium borides 973 K.

\section{Experimental}

\section{Chemicals and Apparatus}

Experiments were carried out in a sealed quartz cell (Figure 1) in the argon atmosphere, purified from traces of moisture and oxygen, which is necessary in order to obtain reliable results.

In three-electrode cell, the working electrode was the tungsten ( $d=1.0 \mathrm{~mm}$, purity > 99.95\%) needle electrode. Tungsten is chosen as the material for the working electrode, since the boron and cerium insoluble therein [11]. As the reference electrode we used quasi-reversible glassy-carbon (SU-2000, d = $2.0 \mathrm{~mm}$ ) rod electrode. The using of glassy-carbon quasi electrode help us to avoid the using of oxygen-diaphragms. Oxide ceramics are not compatible with the halide melts containing rare earth ions. Glassy-carbon quasi-stationary reference electrode, apparently, is a compromise electrode, and is determined by the redox potentials which are established with the participation of the various components of the molten medium. Therefore, its value depends on the melt composition and temperature. Glassy-carbon quasi-stationary reference electrode was used in our studies [4], and previously by the authors [11] in chloride and chloridefluoride melts [12-14]. The auxiliary electrode was the glassy carbon crucible, which was the container for melt at the same time.

Electroreduction of cerium and tetrafluorborate ions was investigated by cyclic voltammetry. The currentvoltage dependence was obtained by the electrochemical complex Autolab PGST 30 (Ecochemic, Holland), which was paired with computer. It has been estimated value of ohmic IR drop in the electrolyte at a time-dependent polarization mode. The specific conductivity of molten potassium, sodium and cesium chlorides is $0.5 \mathrm{ohm}^{-1} \mathrm{~cm}^{-1}$. At the maximum distance of $0.5 \mathrm{~cm}$ between the reference electrode and the working electrode and a current of $10 \mathrm{~mA}$, scanning rate of $10 \mathrm{~V} / \mathrm{s}$ the ohmic drop is about $10-15 \mathrm{mV}$. In addition, the electrochemical complex

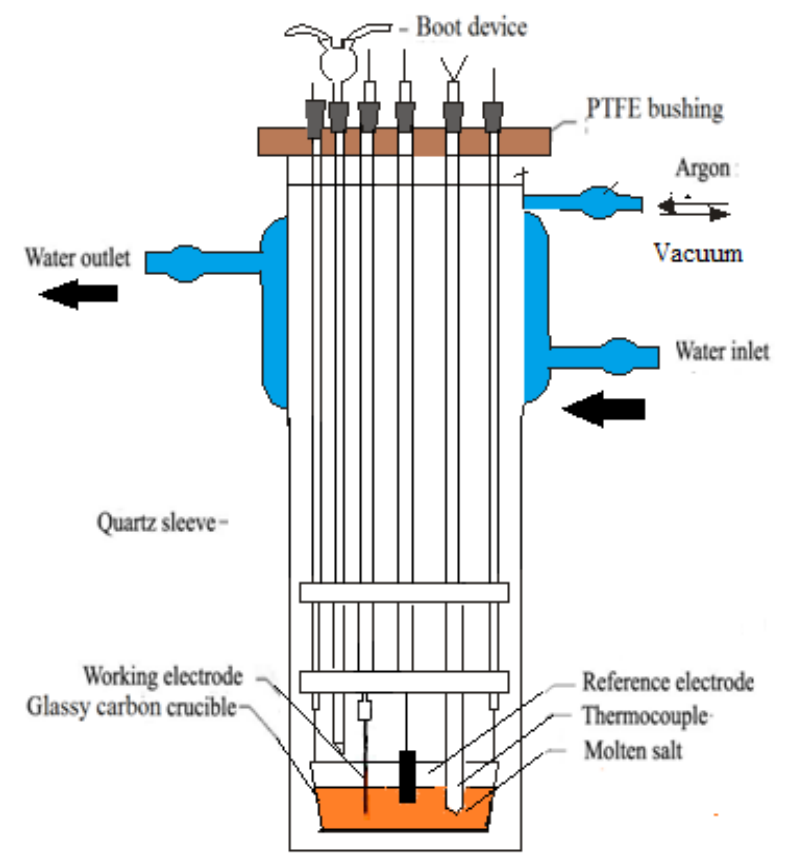

Figure 1. Scheme of high temperature electrochemical quartz cell.

Autolab PGST 30 allows a survey of current-voltage curves with the IR-compensation.

Potentiostatic electrolysis was carried out using a power supply with a current load of up to 5A.

The salts preparation method was following. Sodium and potassium chlorides qualification «analytical grade» were recrystallized, calcined in a muffle furnace, mixed in the desired ratio (an equimolar mixture), and placed in an alundum crucible into glass. A glass cell was evacuated to a residual pressure of $0.7 \mathrm{~Pa}$, first at room temperature and then heated at progressively stepped up to $473^{\circ} \mathrm{C}, 673^{\circ} \mathrm{C}, 873^{\circ} \mathrm{C}$. Then it was filled with inert gas (argon) and melted.

Cerium ion added to the melt in the form of anhydrous cerium trichloride (99.9\%, ultra- dry, Ltd. "Lanchi”). To avoid the formation of oxychlorides, experiments were performed under purified argon and dried in a sealed cell. Potassium tetrafluoroborate $\mathrm{KBF}_{4}$ qualification "reagent grade" was washed in HF, than in ethanol, after than it was dried. All operations with anhydrous salts were carried out in glovebox mBraun Labstar 50 in the argon atmosphere.

Products of electrolysis were identified by DRON-6 and observed by scanning electron microscope (SEM) Vega 3 TESCAN. Particle size was measured by laser diffractive analyzer Fritsch Analysette-22 Nanotech (Germany).

\section{Results and Discussion}

Cyclic current-voltage curves in the $\mathrm{KCl}-\mathrm{NaCl}$ chloride 
melt by adding cerium trichloride and potassium fluoroborate are shown in Figure 2. Curve 1 in this figure represents the voltammogram of background electrolyte - equimolar molten KCl-NaCl. The absence of any waves in it, and low leakage current at relatively high negative potentials allows us to draw conclusions about the cleanliness of the background electrolyte. When we add in the background melt cerium trichloride $\mathrm{C}\left(\mathrm{CeCl}_{3}\right)$ $=4,3 \times 10^{-4} \mathrm{~mol} / \mathrm{cm}^{3}$ (Figure 2(a), curve 2) at potentials $-(2.2 \div 2.3) \mathrm{V}$ relative glassy-carbon quasi-stationary reference electrode on voltammogram appears well reproducible reduction wave of cerium ions. The fluoroborate ions reduction wave observed at potentials $-(1.3 \div$ 1.5) V (Figure 2(b), curve 2).

To determine the sequence of the process of joint electroreduction fluoroborate ion and cerium complex ions tungsten electrode polarization at different potentials of return was held (Figure 3), corresponding to a reduction potential of boron, potential of joint electroreduction and potential recovery of pure cerium. This shooting is possible to correlate the waves observed on the anode and cathode regions of the voltammograms in cyclic polarization.

This picture can be assumed that the shift of reduction potential of complex halide cerium ions to the region of more positive values of the potential was not only due to the changing nature of the substrate, but also the interaction of cerium with the deposited boron observed. Pre-wave, which was observed on the voltammograms before a wave of pure cerium reduction corresponds to the reducing of cerium on deposited boron.

With increasing concentration of fluoroborate ion with respect to the initial concentration of cerium chloride complexes in the cyclic voltammogram (Figure 4) are merged wave electroreduction fluoroborate ion and chloride complexes of cerium in the stretched along the axis

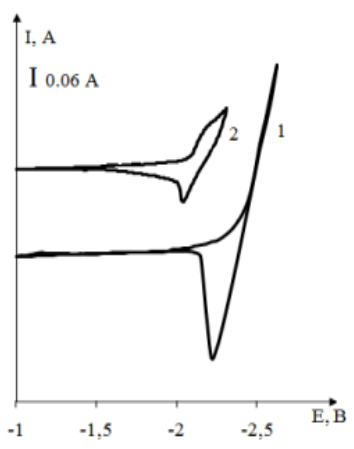

(a)

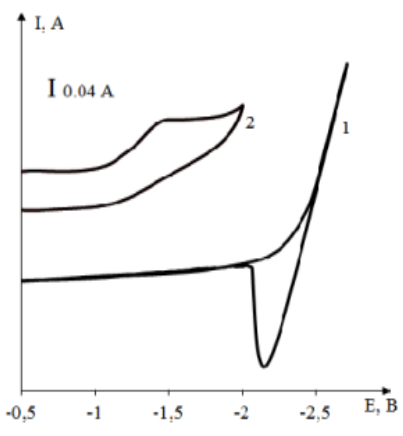

(b)
Figure 2. Cyclic voltammograms of $\mathrm{NaCl}-\mathrm{KCl}$ melt on tungsten electrode (vs $\mathrm{SU}$ ) adding (a) cerium trichloride, $\mathrm{C}\left(\mathrm{CeCl}_{3}\right)=4.30 \times 10^{-4} \mathrm{~mol} / \mathrm{cm}^{3}$ (curve 2). $\mathrm{V}=0.1 \mathrm{~V} / \mathrm{s}$. $\mathrm{S}=$ $0.21 \mathrm{~cm}^{2}$; (b) potassium fluoroborate, $\mathrm{C}\left(\mathrm{KBF}_{4}\right)=3.1 \times 10^{-4}$ $\mathrm{mol} / \mathrm{cm}^{3}$ (curve 2). $\mathrm{V}=0.2 \mathrm{~V} / \mathrm{s} . \mathrm{S}=1.6 \mathrm{~cm}^{2}$. Curve 1, background electrolyte. $T=973 \mathrm{~K}$.

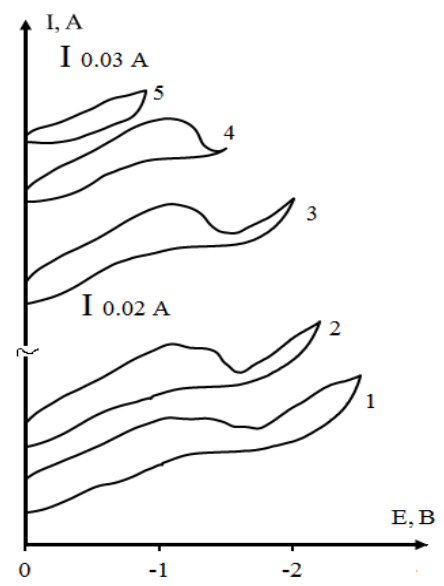

Figure 3. Cyclic voltammograms of NaCl-KCl-CeCl $(3.1 \times$ $\left.10^{-4} \mathrm{~mol} / \mathrm{cm}^{3}\right) \mathrm{KBF}_{4}\left(3.1 \times 10^{-4} \mathrm{~mol} / \mathrm{cm}^{3}\right)$ melt at different return potentials, $\mathrm{V}: 1,(-2,5) ; 2,(-2.2) ; 3,(-2.0) ; 4,(-1.6)$, 5, 1.0. $\mathrm{T}=973 \mathrm{~K} . \mathrm{V}=0.05 \mathrm{~B} / \mathrm{c} . \mathrm{S}=1.6 \mathrm{~cm}^{2}$.

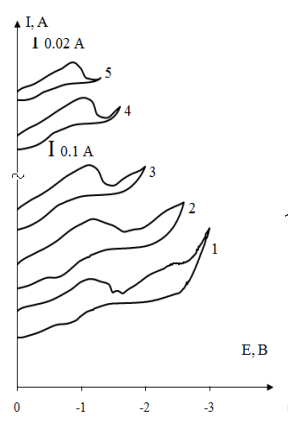

(a)

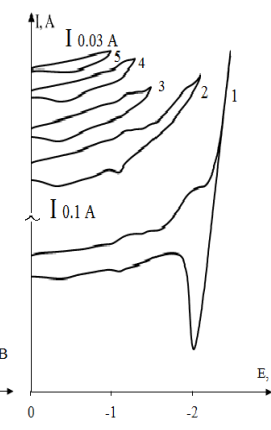

(b)

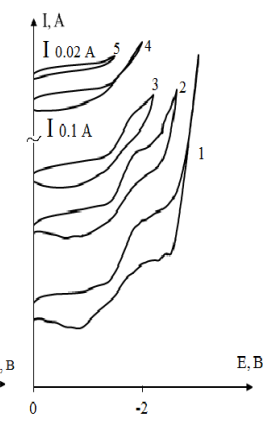

(c)
Figure 4. Cyclic voltammograms at different return potentials, V: 1, 3.0; 2, 2.6; 3, 2.2; 4, 2.0; 5, 1.5. $\mathrm{T}=973 \mathrm{~K} . \mathrm{V}=0.1$ V/s. $\mathrm{S}=1.6 \mathrm{~cm}^{2}$ : a) NaCl-KCl-CeCl $\left(3.1 \times 10^{-4} \mathrm{~mol} / \mathrm{cm}^{3}\right)$ $\mathrm{KBF}_{4}\left(3.1 \times 10^{-4} \mathrm{~mol} / \mathrm{cm}^{3}\right)$; (b) $\mathrm{NaCl}-\mathrm{KCl}-\mathrm{CeCl}_{3}\left(3.1 \times \mathbf{1 0}^{-4}\right.$ $\left.\mathrm{mol} / \mathrm{cm}^{3}\right) \mathrm{KBF}_{4}\left(6.0 \times 10^{-4} \mathrm{~mol} / \mathrm{cm}^{3}\right)$; (c) $\mathrm{NaCl}-\mathrm{KCl}-\mathrm{CeCl}_{3}$ $\left(3.1 \times 10^{-4} \mathrm{~mol} / \mathrm{cm}^{3}\right) \mathrm{KBF}_{4}\left(15 \times 10^{-4} \mathrm{~mol} / \mathrm{cm}^{3}\right)$.

of the wave potentials of reduction, which we attribute to the formation alloys cerium with boron. Further increasing the concentration of fluoroborate ion $\mathrm{n}$ the melt leads to the formation only of boride phases.

Our investigations can be concluded that the electrosynthesis of cerium borides is conducted only in the kinetic mode. Consequently, the electrochemical synthesis process can be represented like successive stages:

- reducing of more electropositive component (boron),

- reducing of more electronegative component (cerium) on pre-selected boron,

- mutual diffusion of cerium and boron to form the different boride phases up to the higher boride $\mathrm{CeB}_{6}$.

The electrochemical processes that occurring during the formation of cerium borides can be represented by the following equations:

$$
\mathrm{BF}^{4-x} \mathrm{Cl}^{\mathrm{x}-}+3 \mathrm{e}^{-} \rightarrow \mathrm{B}+(4-\mathrm{x}) \mathrm{F}^{-}+\mathrm{xCl}^{-}
$$




$$
\begin{aligned}
& \mathrm{CeCl}^{6-y} \mathrm{~F}_{\mathrm{y}}^{3-}+3 \mathrm{e}^{-} \rightarrow \mathrm{Ce}+(6-\mathrm{y}) \mathrm{Cl}^{-}+\mathrm{yF}^{-} \\
& \mathrm{qB}+\mathrm{pCe}=\mathrm{Ce}_{\mathrm{p}} \mathrm{B}_{\mathrm{q}}
\end{aligned}
$$

Results obtained at investigation of the joint electroreduction of cerium halide ions and tetrafluoroborate ions were taken as a basis for the practical implementation of electrochemical synthesis of cerium hexaborides $\mathrm{CeB}_{6}$.

\section{Electrochemical Synthesis of Cerium Boride}

The electrosynthesis of cerium borides nanotubes was performed in a molten mixture of $\mathrm{NaCl}-\mathrm{KCl}-\mathrm{CeCl}_{3}-\mathrm{KBF}_{4}$ at $973 \mathrm{~K}$ on tungsten electrode in the range up -2.4 to $-2.8 \mathrm{~V}$ to relative a quasi-stationary glassy carbon electrode.

The select of electrolytic bath components was done on the basis of thermodynamic analysis and kinetic measurements of joint electrowinning of cerium and boron from halide melts. From the compounds of boron and cerium, which do not contain oxygen, cerium chloride and potassium tetrafluoroborate are fairly low melting point and good solubility in $\mathrm{KCl}-\mathrm{NaCl}$ melt. This solvent was chosen because the decomposition voltage of the molten mixture $\mathrm{KCl}-\mathrm{NaCl}$ more stress decomposition melts $\mathrm{CeCl}_{3}$ and $\mathrm{KBF}_{4}$, and because the alkali metal chlorides are highly soluble in water. These properties are necessary to the washing of cerium borides (Figure 5).

The individual phase of boron, higher boride $\mathrm{CeB}_{6}$ and the mixture of phases, including $\mathrm{CeB}_{4}$ (Figure 6) were obtained in depending on the composition and the synthesis parameters. The purpose of electrosynthesis optimization was to obtain higher boride $\mathrm{CeB}_{6}$ with most valuable properties.

When we chose the concentration ratios of $\mathrm{CeCl}_{3}$ and $\mathrm{KBF}_{4}$, we take into account the first stage of electrosynthesis, during which the reducing of more electropositive boron was done. Electroreduction of the cerium was started when $\mathrm{KBF}_{4}$ concentration was ended. In these temperature conditions the optimum concentration of KBF4 is about $(1.0 \div 1.5) \times 10^{-3} \mathrm{~mol} / \mathrm{cm}^{3}$. According to our study, at higher concentrations of $\mathrm{KBF}_{4}$ the cerium borides getting were complicated by instability of cathode deposit.

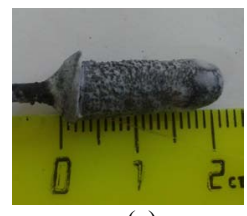

(a)

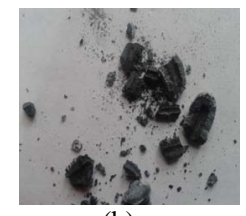

(b)

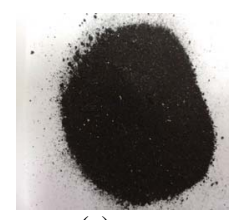

(c)
Figure 5. "Cathode-salt pear" (a), the product of electrolysis before washing (b), and the resulting powder after washing (c).
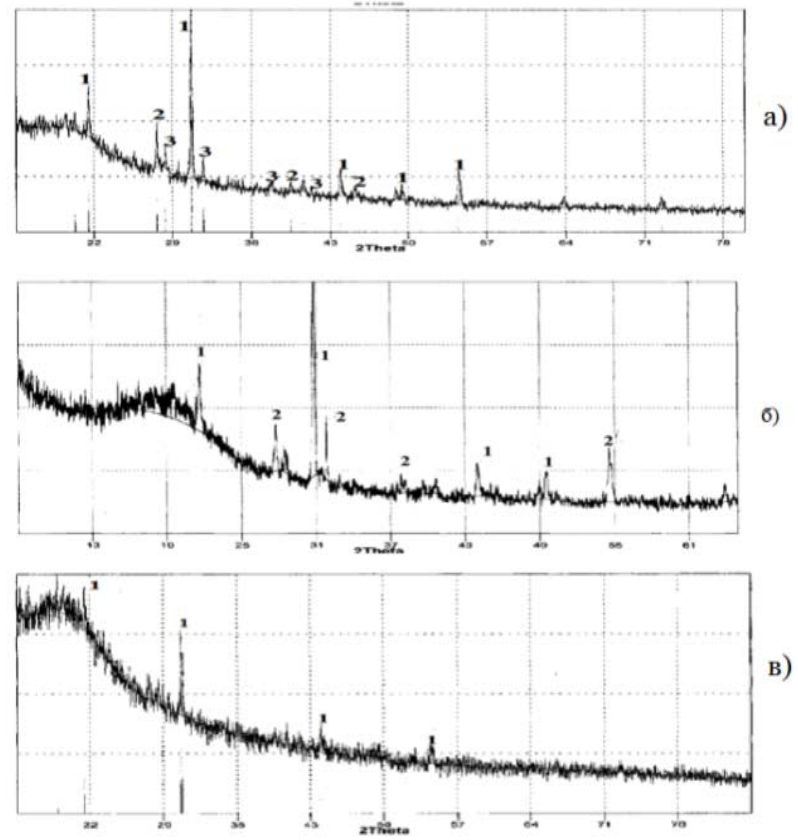

Figure 6. Radiographs of cerium boride powder obtained in $\mathrm{KCl}-\mathrm{NaCl}-\mathrm{CeCl}_{3}\left(3.1 \times 10^{-4} \mathrm{~mol} / \mathrm{cm}^{3}\right) \mathrm{KBF} 4\left(6.0 \times 10^{-4}\right.$ $\mathrm{mol} / \mathrm{cm}^{3}$ ) melt on tungsten electrode. $U=-2.5 \mathrm{~B}$ : a) the line $\left.1, \mathrm{CeB}_{6} ; 2, \mathrm{CeB}_{4} ; \mathrm{b}\right) 1, \mathrm{CeB}_{6} ; 2, \mathrm{CeB}_{4} ; 3, \mathrm{~B}$.

The ceruim borides electrosynthesis was held in potentio and galvanostatic modes. It was observed that these modes are not equal. At galvanostatic electrolysis the true value of the current density is known only in the initial period of time, because during electrolysis varies significantly in cathode area. In most cases we used the potentiostatic electrolysis because the voltage (potential) determines the course of the reactions and monitors the reaction of deposition. If the anode material is glassy carbon and the voltage in the bath $\mathrm{U}<-1.8 \mathrm{~V}$, the cathode deposit consists mainly is boron. Provided the voltage $U=-(1.8-2.5) \mathrm{V}$ the mixture of different phases (B and $\left.\mathrm{CeB}_{4}\right)$ was obtained. If the voltage $\mathrm{U}=-(2.5-2.8) \mathrm{V}$, the cathode deposit consists from higher boride $\mathrm{CeB}_{6}$.

The duration of the electrosynthesis was affected to the composition of the cathode deposits. The data in Table 1 show the dependence of the phase composition of the cathode deposits from the duration of electrolysis in the electrolyte of optimal composition, as well as temperature and voltage.

The optimal duration of the high-temperature electrochemical synthesis for prepare of $\mathrm{CeB}_{6}$ is $90-120$ minutes. Thus, the synthesis of cerium borides was determined by the following interrelated parameters: the composition of the electrolytic bath, the voltage and the temperature. The optimal values of these parameters was as follows: the composition of the melt, wt. \%: $\mathrm{CeCl}_{3}$ $(3.5 \div 7.0), \mathrm{KBF}_{4}(4.5 \div 10.0)$, the rest-mixture of $\mathrm{NaCl}-\mathrm{KCl}$; voltage bath $-(2.6 \div 2.8) \mathrm{V}$, time electrolysis 
is $90 \div 120 \mathrm{~min}$, the temperature is $973 \mathrm{~K}$.

Phase composition of the "cathode-salt pears" identified by X-ray analysis using a DRON-6 (Figure 7).

Particle size was measured by laser diffraction analyzer Fritsch Analysette-22 (Figure 7), and the order of $50-100 \mathrm{~nm}$. The surface of the resulting powders have also examined using the digital scanning electron microscope Vega 3 TESCAN (Figure 8).
The yield of the single-phase $\mathrm{CeB}_{6}$ was $0.20-0.30$ $\mathrm{g} / \mathrm{A} \times$ hour. Specific surface area of ultra-dispersive powders of $\mathrm{CeB}_{6}$ was $5-10 \mathrm{~m}^{2} / \mathrm{g}$.

Our work was focused on the cathode deposit treatment. The comparative radiographs were made before and after different options of the cathode deposit washing.

The experiments showed that the best option of powders

Table 1. Electrochemical synthesis parameters, $T=973 \mathrm{~K}$, cathode $-\mathrm{W}$.

\begin{tabular}{|c|c|c|c|c|}
\hline Electrolyte composition, wt. \% & Voltage E, V & Time $\tau$, min & Phase & Particle size \\
\hline \multicolumn{5}{|l|}{ 1) Molar ratio $\mathrm{CeCl}_{3}: \mathrm{KBF}_{4}=1: 1$} \\
\hline \multicolumn{5}{|l|}{ 2) Molar ratio $\mathrm{CeCl}_{3}: \mathrm{KBF}_{4}=1: 2$} \\
\hline $\mathrm{NaCl}-39.88 ; \mathrm{KCl}-50.75 ; \mathrm{CeCl}_{3}-4.53 ; \mathrm{KBF}_{4}-4.83$ & -2.6 & $80-100$ & $\mathrm{CeB}_{6}$ & $50-70 \mathrm{HM}$ \\
\hline \multicolumn{5}{|l|}{ 3) Molar ratio $\mathrm{CeCl}_{3}: \mathrm{KBF}_{4}=1: 5$} \\
\hline $\mathrm{NaCl}-37.39 ; \mathrm{KCl}-47.59 ; \mathrm{CeCl}_{3}-4.25 ; \mathrm{KBF}_{4}-10.76$ & -2.7 & $90-100$ & $\mathrm{CeB}_{6}$ & $70-90 \mathrm{HM}$ \\
\hline
\end{tabular}

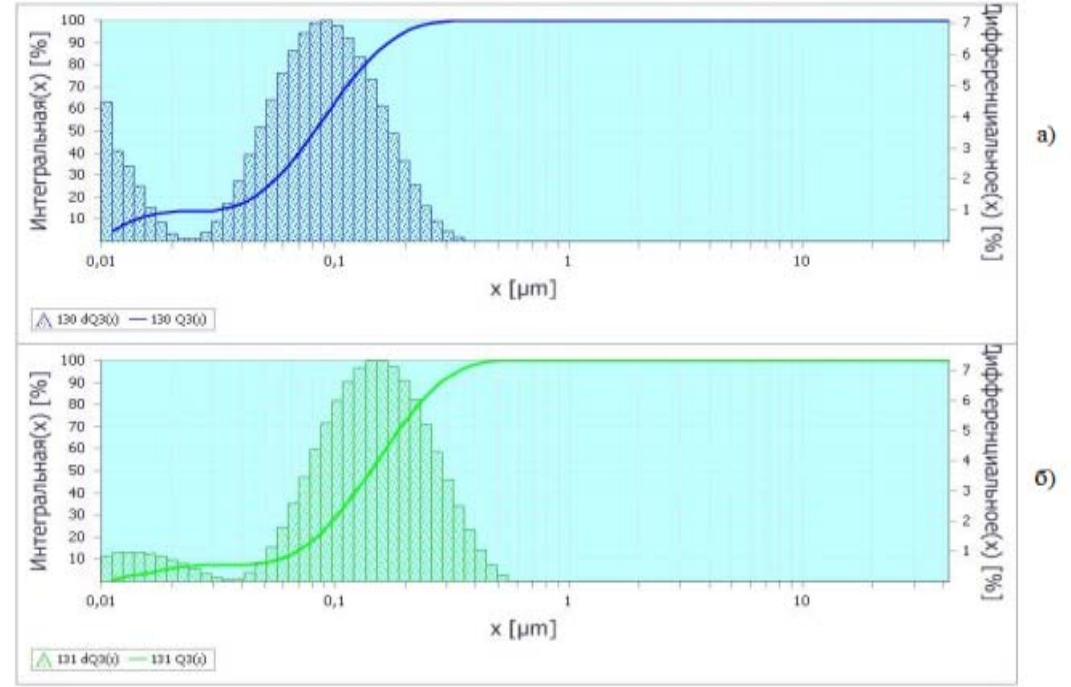

Figure 7. Particle size distribution obtained by the electrochemical synthesis of 973K melt composition, wt.\%: KCl (39.92)$\mathrm{NaCl}$ (50.8)- $\mathrm{KBF}_{4}$ (4.57)- $\mathrm{CeCl}_{3}$ (4.68); $\mathrm{i}=0.3 \mathrm{~A} / \mathrm{cm}^{2}$.
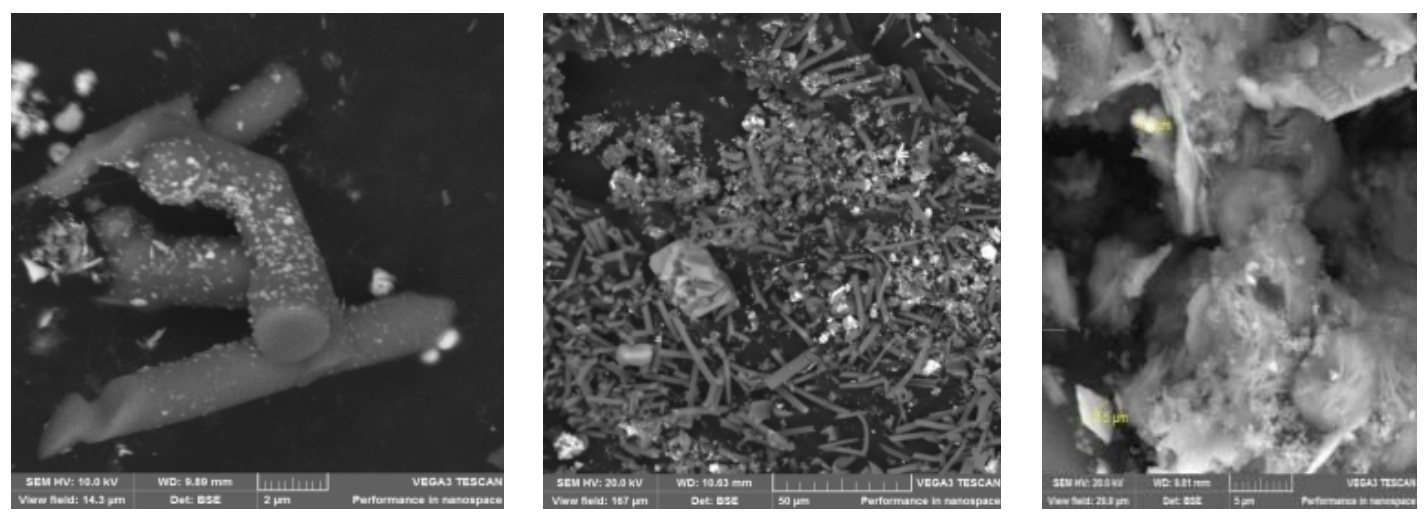

Figure 8. SEM images of the $\mathrm{CeB}_{6}$. 
washing was the washing in distilled water, post-treatment with ammonium hydroxide solution and washing by KF than distilled water by decantation and centrifugation then by washing with double-distilled water.

Thus, to obtain reliable information on the phase composition of the synthesized compounds by electrolysis and the possibility of direct electrochemical synthesis $\mathrm{CeB}_{6}$ nanotubes in halide melts.

\section{Conclusion}

The joint electroreduction of tetrafluorborate and cerium-ions was conducted in equmolar $\mathrm{NaCl}-\mathrm{KCl}$ melt on tungsten electrode at $973 \mathrm{~K}$ by cyclic voltammetry. The analysis of voltammograms was shown that the electrosynthesis in studied systems proceeds in the kinetic mode because reducing potentials of boron and cerium is very different. The results of this research found that under certain conditions, the concentrations of cerium and boron and certain anionic composition of the melt are possible for their joint electroreduction.

Synthesis of cerium borides nanotubes was carried out by potentiostatic electrolysis of molten $\mathrm{KCl}-\mathrm{NaCl}$, containing $\mathrm{CeCl}_{3}$ and $\mathrm{KBF}_{4}$. Electrolysis performed on tungsten electrode in the range of -2.4 to $-2.8 \mathrm{~V}$ relatively of the quasi-stationary glassy-carbon electrode. The influence of the electrolyte composition, temperature, current density, voltage and the duration of electrolysis on the synthesis products was studied. An optimal parameter for getting cerium boride $\mathrm{CeB}_{6}$ nanotubes was found.

\section{Acknowledgements}

The work was done using equipment of Access Center "X-ray diagnosis of materials" with the financial support of the Ministry of Education and Science of Russian Federation, the state contract No. 16552.11.7074.

\section{REFERENCES}

[1] G. V. Samsonov and Y. B. Paderno, "Borides of RareEarth Metals," Kiev. Publishing House "SA USSR", 1961.

[2] P. Taxil, P. Chamelot, L. Massot and C. Hamel, "Electrodeposition of Alloys or Compounds in Molten Salts and Applications," Journal of Mining and Metallurgy, Vol. 39, No. 1-2B, 2003, pp. 177-200.

[3] G. V. Samsonov, "Refractory Compounds of Rare-Earth
Metals and Non-Metals,” Publishing House Metallurgie, Moscow, 1964, pp. 53-55.

[4] M. K. Vindizheva, R. A. Karashaeva, S. A. Shermetova, et al., "The Investigation of Mechanism of Joint Electroreduction Cerium-Ionsand Fluoroborate-Ions in NaClKCl-CsCl Melt,” Scientific Works of Young Scientists, Nalchik, 2006, pp. 293-295.

[5] Kh. B. Kushkhov, M. K. Vindizheva, R. A. Mukozheva and M. R. Tlenkopachev, "The High Temperature Electrochemical Syntheses of Refractory Compounds of Samarium and Boron in Halide Melts," Izvestiya KBSU, Vol. 1, No. 2, 2011, pp. 29-34.

[6] Kh. Kushkhov, M. Vindizheva, R. Mukozheva, M. Nafonova and M. Tlencopachev, "The Electrochemical Syntheses of Lanthanum Borides in Halide Melts,” Materials of XV Russian Conference of Physical Chemistry and Electrochemistry Molten Salts and Solid Electrolytes, Nalchik, 2010 , pp. 181-182

[7] O. V. Chemezov, "Electrochimiskoe Povedenie Bora v Khloridnih I Khloridno-Ftoridnih Rasplavah,” Avtoref. diss. kand. chim. Nauk, Sverdlovsk, 1987, 17 p.

[8] V. Danek, L. Votava and B. Matisovsky, "Reactions of Potassium tetrafluorocborate in Molten Alkali Chlorides," Chem. Izvestiya, Vol. 30, 1976, pp. 377-383.

[9] L. P. Polyakova, G. A. Bukatova, E. G. Polyakov, E. Christensen, J. H. von Barer and N. J. Bjerrum, "Electrochemical Behaviour of Boron in LiF-NaF-KF-Melts," Journal of The Electrochemical Society, Vol. 143, No. 10. 1996, pp. 3178-3186. http://dx.doi.org/10.1149/1.1837184

[10] P. Fellner, M. Makita, K. Matishovski and A. Silny, “The Mechanism of Kathodic Process at Electrodeposition of Boron from Ionic Melts," $V$ Conference of Socialist Countries in Chemistry of Ionic Melts, Kiev, 1984, p. 43.

[11] F. A. Shank, "Structure of Double Alloys,” Metallurgy Ltd., Moscow, 1973, p. 45.

[12] S. A. Kuznetsov, H. Hayashi, K. Minato and M. GauneEscard, "Electrochemical Behavior and Some Thermodynamic Properties of $\mathrm{UCl}_{4}$ and $\mathrm{UCl}_{3}$ Dissolved in a LiCl-KCl Eutectic Melt,” Journal of The Electrochemical Society, Vol. 152, 2005, p. 203. http://dx.doi.org/10.1149/1.1864532

[13] S. A. Kuznetsov and M. Gaune-Escard, "Kinetics of Electrode Processes and Thermodynamic Properties of Europium Chlorides Dissolved in Alkali Chloride Melts,” Journal of Electroanalytical Chemistry, Vol. 595, 2006, p. 11. http://dx.doi.org/10.1016/j.jelechem.2006.02.036

[14] S. A. Kuznetsov, "Molten Salts: From Fundamentals to Applications,” M. Kluwer Acad. Publ., Norwell, Vol. 52, 2002, p. 283. 